\title{
Application of Thiosemicarbazide Based Schiff Base Ligands as Ionophore in PVC Metrix for Potentiometric Sensor Development
}

\section{Chandra Mohan*}

Department of Chemistry, K R Mangalam University, India

*Corresponding author: Chandra Mohan, Department of Chemistry, K R Mangalam University, Gurgaon 122103, Haryana, India, Email: chandra.mohan@krmangalam.edu.in

\section{Short Communication}

Volume 3 Issue 1

Received Date: December 17, 2018

Published Date: January 18, 2019

DOI: $10.23880 /$ macij- 16000130

\section{Abstract}

The main objective of this work is to provide information on the development of ion selective electrodes (ISEs) based on PVC membrane by incorporating Schiff base ligands and their complexes as ionophores for sensing different metals ion. Ion selective electrodes can be prepared and the electrodes performance may optimized by varying the amounts of PVC, plasticizers and cation/anion excluders. Various characteristic features of chemical sensors with different parameters such as response time, selectivity, lifetime and $\mathrm{pH}$ effect on sensor response have been reported. The proposed ISEs have been successfully applied to determine cations and anions and as electrode in potentiometric titrations.

Keywords: PVC Membrane; Ion-selective Electrode; Membrane Electrode; Schiff Bases; Thiosemicarbazide; Semicarbazide

\section{Introduction}

Ion selective electrodes (ISE) are one of the most frequently used potentiometric sensors during laboratory analysis as well as in industry, process control, physiological measurements, and environmental monitoring [1-6]. In ISE's, Signal is generated by the charge separation at the interface between the membrane and the solution, due to the selective partitioning of ionic species between these two phases. In past two decades, there has been a growing interest in search for ionophores (electroactive material) that can chemically recognize specific ion and offers new or improved selectivity for different ions [7].
The main components of membrane in ion selective potentiometric sensors are a polymeric matrix, a membrane solvent mediator, an ionic additive and an ion sensory molecule. All these components and their relative amounts influence the characteristics of these types of sensors. Ionophore and plasticizer in a PVC membrane plays a key role in the performance of an ion selective electrode [8].

Schiff bases derived from thiosemicarbazide may be very useful as ionophores because of their significant electrochemical and biochemical activity in liquid membrane. Schiff bases are the products of condensation of arylamines and carbonyl compounds [9]. They are quite stable and versatile intermediates for preparation of 


\section{Medicinal \& Analytical Chemistry International Journal}

a number of important medicinal compounds. Schiff base ligands have also been for the synthesis of metal complexes with different metal ions [10-12].

A series of new Schiff base derivatives were synthesized with thiophene-2-aldehyde and acetyl-2thiophene. These Schiff base ligands have been used as ionophore for the preparation of PVC membrane for the fabrication of Ion-selective electrodes (ISEs). The ISEs have widely been used as chemical sensors for various metal ions.

\section{References}

1. Cragg A, Mody G J, Thomas JDR (1974) PVC matrix membrane ion-selective electrodes. Construction and laboratory experiments. J Chem Edu 51(8): 541.

2. Mohan C, Sharma K, Chandra S (2017) A Zinc(II) PVCMembrane Sensor Based On Synthesized Thiophene2-Aldehyde Semicarbazone (TAS) As An Ionophore. Jordan Journal of Chemistry 12(1): 39-50.

3. Zamani HA, Ganjali MR, Norouzi P, Meghdadi S (2008) Application of Novel Praseodymium (III) PVC-Membrane Electrode for Determination of Pr (III) Ions in Soil and Sediment Samples. Anal Lett 41(5): 902-916.

4. Macca C (2004) Acta Response time of ion-selective electrodes: Current usage versus IUPAC recommendations. Anal Chim 512(2): 183-190.

5. Shamsipur M, Hosseini M, Alizadeh K, Mousavi MF, Garau A, et al. (2005) PVC Membrane Potentiometric
Sensor Based on 5-Pyridino-2,8-dithia[9](2,9)-1,10phenanthroline-phane for Selective Determination of Neodymium(III). Anal Chem 77(1): 276-283.

6. Mohan C, Sharma K, Chandra S (2017) Cd(II) ionselective electrode based on 2-acetylthiophene Semicarbazone in Polymeric membrane. Anal \& Bioanal Electrochem 9(1): 35-46.

7. Bakker E, Pretsch E (2005) Potentiometric sensors for trace-level analysis. Trends in Anal Chem 24(3): 199-207.

8. Gupta VK, Khayat MA, Minocha AK, Kumar P (2005) Zinc(II)-selective sensors based on dibenzo-24crown-8 in PVC matrix. Anal Chim Acta 532(2): 153158.

9. Mohan C, Kumar V, Kumari S (2018) Synthesis, characterization, and antibacterial activity of the schiff bases derived from thiosemicarbazide, 2-acetyl thiophene and thiophene- 2 aldehyde. Int Res J Pharm 9(7): 153-158.

10. Ion AC, Bakker E, Pretsch E (2001) Potentiometric $\mathrm{Cd}^{2+}$-selective electrode with a detection limit in the low ppt range. Anal Chim Acta 440(2): 71-79.

11. Koryta J (1986) Ion-Selective Electrodes. Ann Rev Mater Sci 16: 13-27.

12. Smyth MR, Vos JG (1986) Electrochemistry, Sensors \& Analysis. Elsevier Science Publisher, Amsterdam. 